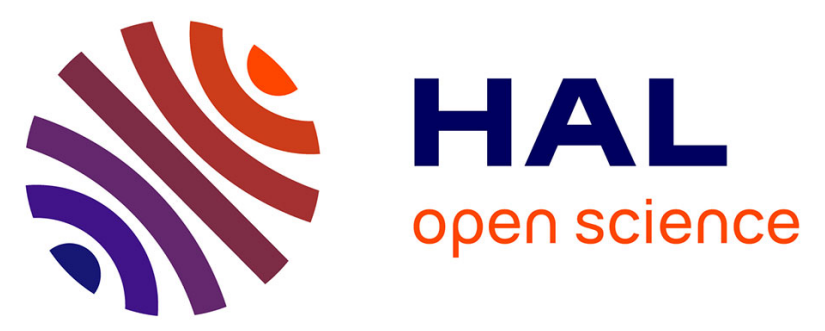

\title{
Vitamin D Supplementation in France in patients with or at risk for osteoporosis Recent data and new practices
}

Jean-Claude Souberbielle, Catherine Cormier, Etienne Cavalier, Véronique Breuil, Françoise Debiais, Patrice Fardellone, Pascal Guggenbuhl, Rose-Marie Javier, Erick Legrand, Eric Lespessailles, et al.

\section{To cite this version:}

Jean-Claude Souberbielle, Catherine Cormier, Etienne Cavalier, Véronique Breuil, Françoise Debiais, et al.. Vitamin D Supplementation in France in patients with or at risk for osteoporosis Recent data and new practices. Joint Bone Spine, 2020, 87 (1), pp.25-29. 10.1016/j.jbspin.2019.04.004 . hal-02152873

\section{HAL Id: hal-02152873 \\ https://hal-univ-rennes1.archives-ouvertes.fr/hal-02152873}

Submitted on 21 Jun 2019

HAL is a multi-disciplinary open access archive for the deposit and dissemination of scientific research documents, whether they are published or not. The documents may come from teaching and research institutions in France or abroad, or from public or private research centers.
L'archive ouverte pluridisciplinaire HAL, est destinée au dépôt et à la diffusion de documents scientifiques de niveau recherche, publiés ou non, émanant des établissements d'enseignement et de recherche français ou étrangers, des laboratoires publics ou privés. 


\section{Vitamin D Supplementation in France in Patients with or at Risk for Osteoporosis: \\ Recent Data and New Practices}

Jean-Claude Souberbielle ${ }^{1}$, Catherine Cormier ${ }^{2}$, Etienne Cavalier $^{3}$, Véronique Breuil ${ }^{4}$, Françoise Debiais ${ }^{5}$, Patrice Fardellone ${ }^{6}$, Pascal Guggenbuhl ${ }^{7}$, Rose-Marie-Javier ${ }^{8}$, Erick Legrand $^{9}$, Eric Lespessailles ${ }^{10}$, Julien Paccou ${ }^{11}$, Thierry Thomas ${ }^{12}$, Bernard Cortet $^{11}$ au nom du Groupe de recherche et d'information sur les ostéoporoses (GRIO)

1- Service d'explorations fonctionnelles, Hôpital Necker-Enfants malades, AP-HP, 75015, Paris, France

2- Rheumatology Unit, Cochin Hospital, 27, rue du Faubourg Saint-Jacques, 75014 Paris, France

3- Department of Clinical Chemistry, UnilabLg, CIRM, University of Liège, CHU de Liège, Domaine du Sart-Tilman, 4000 Liège, Belgium

4- Université Côte D’Azur, Service de Rhumatologie-CHU de Nice, BIAM- UMR E 4320 TIRO-MATOs, CEA/UNS, Centre Hospitalier Universitaire Nice, 06000 Nice, France

5- Service de rhumatologie, CHU de Poitiers, 86021 Poitiers, France

6- Service de rhumatologie, CHU Amiens- Hôpital Nord, Place Victor Pauchet - 80054 Amiens cedex 1, France

7- Institut NUMECAN, Inserm U 1241, Inra U 1341, 35000 Rennes, France, Service de rhumatologie, hôpital Sud, CHU, 35000 Rennes, France, Université de Rennes 1, 35000 Rennes, France

8- Service de rhumatologie, Hôpitaux universitaires de Strasbourg, Hôpital de Hautepierre, 1 avenue Molière, 67200 Strasbourg, France 
9- Service de rhumatologie, CHU d'Angers, 49000 Angers, France

10- Service de rhumatologie, CHR Orléans, EA 4708 I3MTO, Université d'Orléans, 45067 Orléans, France

11- Service de rhumatologie, CHU Lille et EA 4490, Université de Lille, 59000 Lille, France

12- INSERM U1059, service de rhumatologie, CHU de Saint-Étienne, 42100 SaintÉtienne, France

Correspondence: Bernard Cortet : bernard.cortet@ chru-lille.fr

\section{Graphical Abstract}

\section{In patients with or at risk for osteoporosis}

Until daily dosing becomes feasible, intermittent dosing should remain standard practice, with the lowest available dosages and shorter dosing intervals. This strategy probably improves adherence compared to daily dosing.

- Start with a loading phase

$50000 \mathrm{IU}$ of vitamin $\mathrm{D} 3$ per week for $\mathbf{8}$ weeks in patients whose $25 \mathrm{OHD}$ is $<20 \mathrm{ng} / \mathrm{mL}$

$50000 \mathrm{IU}$ of vitamin D3 per week for 4 weeks in patients whose 25OHD is between 20 and $30 \mathrm{ng} / \mathrm{mL}$

- After this loading phase, prescribe long-term supplementation:

$50000 \mathrm{IU}$ of vitamin D3 per month

- After 3-6 months of this long-term supplementation, repeat the 250HD assay

If $250 H D$ is still $<\mathbf{3 0} \mathbf{n g} / \mathbf{m L}$

- either shorten the dosing interval (e.g., 50000 IU every 2 weeks)

- or increase the dosage (e.g., to $\mathbf{8 0 0 0 0}$ or $\mathbf{1 0 0 0 0 0 ~ I U ~ e a c h ~}$ month)

If $250 \mathrm{HD}$ is $>60 \mathrm{ng} / \mathrm{mL}$ (extremely rare)

- The only possibility contradicts the recommendations above:

- increase the dosing interval (e.g., 50000 UI every 2 months) until lower dosages become available 


\begin{abstract}
With intermittent vitamin D supplementation, serum 25-hydroxyvitamin D (25OHD) levels may remain stable only if the dosing interval is shorter than 3 months, the ideal perhaps being about 1 month. Recent data support moderate daily vitamin D doses instead of high intermittent doses, notably in elderly patients prone to falls. The level of evidence is low, however, with no head-to-head comparisons of clinical outcomes such as fractures and falls in groups given identical dosages daily versus intermittently. A challenge to daily vitamin D supplementation in France is the absence of a suitable pharmaceutical formulation. In addition, daily dosing carries a high risk of poor adherence. Until suitable vitamin D3 formulations such as tablets or soft capsules each containing 1000 or 1500 IU become available, we suggest intermittent supplementation according to 2011 GRIO guidelines. Among the available dosages, the lowest should be preferred, with the shortest possible interval, e.g., 50000 IU monthly rather than 100000 every two months.
\end{abstract}

Keywords: Vitamin D. Osteoporosis. Muscle. Falls. Bone metabolism. Fractures. 


\section{Introduction}

In 2011, the French Osteoporosis Research and Information Group (Groupe de Recherche et d'Information sur l'Ostéoporose, GRIO) issued recommendations about vitamin D supplementation in adults [1]. Since then, new data have emerged, causing changes to former concepts. Thus, 24-hydroxylation is now recognized as a major vitamin D-inactivation pathway, new clinical definitions of vitamin D deficiency and vitamin D insufficiency have been developed, and technical advances have been achieved including the development of a reference standard procedure for assaying 25-hydroxy-vitamin D (25OHD). Furthermore, the French statutory health insurance system no longer reimburses serum 25OHD assays under all circumstances. However, the main reason for this update explaining recent changes in our approach is that new evidence challenges current vitamin D supplementation modalities, notably the intermittent administration of high dosages.

Vitamin D contributes to regulate calcium and phosphate metabolism and makes a key contribution to musculoskeletal health. Effects of vitamin D include increased intestinal absorption of calcium and phosphate; stimulation of fibroblast growth factor 23 (FGF23) expression; regulation, in synergy with parathyroid hormone (PTH), of distal renal tubule calcium reabsorption and bone turnover; and regulation of PTH release via a feedback loop. Profound vitamin D deficiency results in defective bone mineralization, rickets, osteomalacia, and diffuse muscle pain. In several randomized placebo-controlled trials, vitamin D supplementation, usually given in conjunction with calcium supplementation, decreased the risk of nonvertebral fractures in patients older than 65 years [2] and the risk of falls in those older than 70 years [3], provided the daily vitamin D intake was at least $20 \mu \mathrm{g}$ (800 IU) and the serum $25 \mathrm{OHD}$ level was about $30 \mathrm{ng} / \mathrm{mL}$. Furthermore, osteoporosis medications that act 
by inhibiting bone resorption, such as bisphosphonates, are fully effective only in patients whose serum $25 \mathrm{OHD}$ is at least $30 \mathrm{ng} / \mathrm{mL}$ [4].

In addition to these well-demonstrated effects, vitamin D may have other benefits. Thus, numerous observational and experimental studies suggest that vitamin D may prevent a range of health conditions including diabetes, cardiovascular disease, certain types of cancer, agerelated cognitive decline, infections, and autoimmune diseases [5]. However, controlled interventional studies usually failed to confirm these nonclassical effects of vitamin D, except in patients who were vitamin D-deficient at baseline [6] and in those who achieved the target serum 25OHD levels defined for the study [7]. Here, we will confine our discussion to the musculoskeletal effects of vitamin D in an attempt to define the optimal vitamin D status and adequate vitamin D intake.

\section{Defining the optimal vitamin D status}

The optimal vitamin D status is defined based on the serum 25OHD level. Reference ranges for laboratory parameters are usually defined as the range that includes $95 \%$ of the values found in a healthy population. This method cannot be used for serum 25OHD levels, however: as 25OHD levels are significantly lower in winter than in summer, two different normal ranges would have to be defined. Consequently, experts agree that a better approach consists in determining 25OHD cutoffs below and above which deleterious effects may occur, as well as the 25OHD levels associated with beneficial effects, based on the available interventional studies. Various cutoffs have been put forward in recommendations about managing patients with vitamin D stores. A consensus exists about defining vitamin D deficiency as a serum 25OHD level below 10-12 ng/mL, whereas some uncertainty continues 
to surround the definition of vitamin D insufficiency. It is useful to distinguish two main situations depending on the risk of osteoporosis.

\subsection{Patients with osteoporosis or at high risk for osteoporosis}

In patients who have osteoporosis or are at high risk for osteoporosis due to treatments with potentially deleterious bone effects (e.g., high-dose glucocorticoids, aromatase inhibitors, and GnRH analogs) or to health conditions (e.g., primary hyperparathyroidism or other endocrinopathies; or malabsorption related to celiac disease, cystic fibrosis, or bypass bariatric surgery), patients with chronic kidney disease, and older patients at high risk for falls, many experts believe that the serum $25 \mathrm{OHD}$ level must be kept at or above $30 \mathrm{ng} / \mathrm{mL}$ (75 nmol/L) to optimize musculoskeletal strength [1;8-11]. Serum 25OHD assays are warranted, before starting the supplementation then during follow-up to adjust the dosage. In this patient subset, the GRIO has recommended a loading phase to allow the rapid and accurate interpretation of parameters reflecting the calcium and phosphate status, notably the serum PTH level. Importantly, a calcium intake of about $1 \mathrm{~g} /$ day should be provided in these patients.

\subsection{The general population of apparently healthy individuals}

For this patient population, the Institute of Medicine in the US recommends supplying the vitamin D dose that will allow most individuals to achieve a serum 25OHD level of 20 $\mathrm{ng} / \mathrm{mL}(50 \mathrm{nmol} / \mathrm{L})$, which is deemed sufficient in this situation [12]. No prior serum $25 \mathrm{OHD}$ assay is required.

The upper limit of the desirable serum $25 \mathrm{OHD}$ range is currently set at $60 \mathrm{ng} / \mathrm{mL}$, which is approximately the highest value found in populations exposed to generous amounts of UVB radiation from sunlight year-round [13]. The $60 \mathrm{ng} / \mathrm{mL}$ value is also markedly 
different from the lowest value at which vitamin D poisoning may occur, i.e., $150 \mathrm{ng} / \mathrm{mL}$ [14]. Another point of interest is that a few observational studies found an upside-down J-shaped relationship between the $25 \mathrm{OHD}$ level and the relative risk of disease: the risk was higher not only in patients with low values, but also, to a lesser extent, in those with values above 60 $\mathrm{ng} / \mathrm{mL}$ [15]. Although these observational studies cannot supply information about causality, their findings support the choice of $60 \mathrm{ng} / \mathrm{mL}$ as the highest desirable serum 25OHD level.

Studies in the general population in France have found serum 25OHD levels below $20 \mathrm{ng} / \mathrm{mL}(50 \mathrm{nmol} / \mathrm{L})$ in about $40 \%-50 \%$ of individuals and below $30 \mathrm{ng} / \mathrm{mL}$ ( $75 \mathrm{nmol} / \mathrm{L})$ in $80 \%$ of individuals [16-18].

\section{Vitamin D supplementation}

The goals of vitamin D supplementation are to ensure that serum 25OHD levels are between 20 and $60 \mathrm{ng} / \mathrm{mL}$ in most individuals in the general population and between 30 and $60 \mathrm{ng} / \mathrm{mL}$ in patients with osteoporosis, chronic kidney disease, or malabsorption. Until very recently, standard practice consisted in obtaining a serum 25OHD assay to guide selection of the vitamin D dose. Thus, higher doses were given to patients with lower serum $25 \mathrm{OHD}$ values. This practice made sense but resulted in a large number of 25OHD assays, at considerable cost to the healthcare system. The French National Authority for Health (HAS) therefore decided to reimburse serum 25OHD assays only for individuals meeting specific criteria (http://www.has-sante.fr/portail/jcms/c_1356838/fr/utilite-clinique-du-dosage-de-lavitamine-d-rapport-d-evaluation). Many experts feel that these criteria are overly restrictive [19].

Whereas calcium supplements must be taken every day, vitamin D supplements can be taken at far wider intervals, due to the long half-life of 25OHD. In France, preparations are 
available for either daily or intermittent administration. Drops for supplying small daily doses (300-400 IU of vitamin D per drop) are chiefly used for infants. Tablets and sachets combining vitamin D3 and calcium are also available. For intermittent administration, the dosages available in France are 50 000, 80 000, 100 000, and 200000 IU for vitamin D3 and $600000 \mathrm{IU}$ for vitamin D2. Patient adherence to daily vitamin D supplementation, notably in combination with calcium, is often low [20]. Consequently, intermittent administration is currently the preferred method in France. With intermittent administration, two rules must be scrupulously followed: only vitamin D3 should be used, as it maintains an optimal vitamin D status for far longer than does vitamin D2 [21]; and very high doses at widely spaced intervals should not be used, particularly in older women. The second rule is based on several studies. In women older than 80 years, a single annual dose of 500000 IU of vitamin D3 given for 4 consecutive years increased the risk of both fractures and falls compared to a placebo [22]. The excess fractures and falls was significant only during the first 3 months after each annual dose. Although surprising, these findings confirm those of a previous study in which men and women older than 75 years had a higher hip fracture rate when given annual intramuscular injections of $300000 \mathrm{IU}$ of vitamin D2 instead of a placebo [23].

In France, when prescribing intermittent vitamin D supplementation in doses of 80000 or $100000 \mathrm{IU}$, the usual dosing interval is 2 to 3 months, in keeping with earlier recommendations [1]. Recent data, however, suggest that a shorter interval may be preferable. A randomized controlled trial done in postmenopausal women in Finland compared 25OHD levels before and 7 days after treatment with either a placebo or with vitamin D3 in a dosage of $100000 \mathrm{IU}$ or $200000 \mathrm{IU}$ [24]. Each treatment was given at 3-month intervals. The 25OHD levels 7 days after dosing were higher in the $200000 \mathrm{IU}$ group than in the $100000 \mathrm{IU}$ group, as expected, but the $25 \mathrm{OHD}$ levels just before the next dose were the same in the two vitamin D3 groups. The key messages from this study are that a steeper rise in vitamin D 
levels induced by supplementation is followed by a steeper decline, and a 3-month interval between $100000 \mathrm{IU}$ or $200000 \mathrm{IU}$ doses may allow marked fluctuations in 25OHD levels, suggesting that a shorter interval may be preferable. This last point is important, as recent studies have shown that fluctuations in 25OHD levels are associated with variations in the opposite directions in serum levels of PTH and CTX: PTH and CTX levels increase when 25OHD levels decrease, indicating increased bone resorption that probably adversely affects bone health [25].

In several studies, 25OHD levels remained similarly stable with daily and monthly dosing [26]. A recent randomized trial, however, calls this finding into question. The participants were 200 elderly individuals ( $67 \%$ of females) with at least one fall during the past year [27]. The treatments were given once a month. One group received $60000 \mathrm{IU}$ (the theoretical equivalent of 2000 IU/day) of vitamin D3 and another only 24000 IU of vitamin D3. The mean number of falls was significantly higher in the group given the higher dose. One possible explanation is that the excess falls were caused by the higher vitamin D3 doses and/or higher 25OHD levels. However, a randomized controlled trial done a few years earlier by the same group suggests that the intermittent dosing schedule may be the culprit [28]. Mean age and proportion of female participants were similar to those in the subsequent study, and the inclusion criterion was a recent hip fracture. The fall risk was similar in the groups given 800 IU/day and 2000 IU/day. In contrast, readmissions and complications of falls were significantly less common in the group given the higher dose.

Although definitive data are still lacking, the available studies raise many questions regarding the best vitamin D supplementation regimen, notably in older individuals. Daily dosing instead of the monthly administration of higher doses has been advocated in an editorial [29] and a position paper [30]. Several older publications also recommended daily dosing [31;32]. Furthermore, metaanalyses assessing the effects of vitamin D supplementation 
on muscle strength [33] or on the risk of respiratory tract infections [34] found that vitamin D supplementation was beneficial when given daily but not when given in high doses at wide intervals.

\section{Conclusion and perspectives}

A few recent studies suggest that moderate daily doses of vitamin D may be preferable over larger doses given intermittently in patients who fall. The level of evidence underlying this suggestion is low, however. More specifically, no head-to-head comparisons of clinical outcomes such as fractures and falls with daily versus intermittent administration of the same dosages has been published to date. In addition, daily dosing is challenging given the lack of a suitable pharmaceutical formulation and high risk of nonadherence. Similar doses of vitamin D given daily or intermittently seem to induce the same decrease in PTH release, an effect that is central to the efficacy of vitamin D in improving bone health. A reasonable suggestion at present is intermittent supplementation using the lowest available doses and shortest possible dosing intervals. For instance, in patients with falls and/or osteoporosis, for whom the target is a $25 \mathrm{OHD}$ level above $30 \mathrm{ng} / \mathrm{mL}$, the dosage could be determined according to the baseline 25OHD level, namely, $50000 \mathrm{IU} /$ week for 8 weeks if below $20 \mathrm{ng} / \mathrm{mL}$ and 50000 IU/week for 4 weeks if between 20 and $30 \mathrm{ng} / \mathrm{mL}$ (Figure 1). This loading phase can be followed by the long-term administration of $50000 \mathrm{IU} / \mathrm{month}$. A 25OHD assay after 3-6 months is then necessary to determine whether the dosage needs to be adjusted, given the huge interindividual variability in the $25 \mathrm{OHD}$ response to vitamin $\mathrm{D} 3$, which ranges from minimal to very considerable [35]. If the $25 \mathrm{OHD}$ level remains below $30 \mathrm{ng} / \mathrm{mL}$, the dosing interval can be shortened or the dosage increased to 80000 or 100000 IU each month. If the $25 \mathrm{OHD}$ level is above $60 \mathrm{ng} / \mathrm{mL}$, the only available strategy to date, despite being in 
contradiction to the comments above, consists in lengthening the dosing interval (e.g., 50000 IU every 2 months), until lower dosages (e.g., 25000 IU) become available.

Should pharmaceutical forms suitable for daily supplementation become available (e.g., tablets or soft capsules containing 1000 or 1500 IU of vitamin D3), patients displaying good treatment adherence could take a daily dose determined based on the 25OHD level. Thus, for patients with $25 \mathrm{OHD}$ levels below $20 \mathrm{ng} / \mathrm{mL}, 3000$ to $5000 \mathrm{IU} /$ day for about 3 months could be followed by long-term supplementation with 1000 to 3000 IU/day, with adjustments based on follow-up 25OHD assays. These suggested treatment regimens are consistent with previous recommendations issued by the GRIO [1], which also include intermittent.

\section{Disclosure of interest}

Souberbielle JC: fees for occasional interventions as an expert or speaker for Diasorin, Roche Diagnostics, Abbott, Amgen, Shire, MSD, Lilly, and Mylan

Cormier C: fees for occasional interventions as an expert or speaker for Amgen, Lilly, and Shire

Cavalier E: fees for occasional interventions as an expert or speaker for Diasorin, IDS, Roche, Abbott, and Amgen

Breuil V: fees for occasional interventions as an expert or speaker for Amgen, Lilly, and UCB

Debiais F: fees for occasional interventions as an expert or speaker for Abbot, Alexion, Amgen, Lilly, MSD, Pfizer, Roche, Novartis, and Theramex

-Fardellone P: fees for occasional interventions as an expert or speaker for Amgen, Expanscience, Lilly, Novartis, Mylan, MSD, Pfizer, Théramex, and UCB; indirect financial ties: funding for research projects or as an investigator from Roche-Chugaï, Biogen, and Abbvie 
Guggenbuhl P: fees for occasional interventions as a speaker or attendee at conventions from Amgen, Lilly, and Novartis

Javier RM has no conflicts of interest to declare.

Legrand E: fees for occasional interventions as an expert or speaker for Amgen and Lilly

Lespessailles E: fees for occasional interventions as an expert or speaker for Amgen, Celgène, Expanscience, Lilly, MSD, Novartis UCB, and Amgen; indirect financial ties: funding for research projects or as an investigator from AbbVie, Amgen, Celgène, Eli Lilly, MSD, and UCB

Paccou J: fees for occasional interventions as an expert or speaker for Amgen, Lilly, Janssen, MSD, Pfizer, UCB, and Novartis

Thomas T: occasional interventions for Amgen, Chugaï, Expanscience, Gilead, HAC-Pharma, LCA, MSD, Novartis, Pfizer, Thuasne, UCB, Abbvie, BMS, Lilly, TEVA, and Medac Cortet B: fees for occasional interventions as an expert or speaker for Amgen, Expanscience, Ferring, Lilly, Medtronic, MSD, Mylan, Novartis, Roche Diagnostics, and UCB 


\section{References}

1- Benhamou CL, Souberbielle JC, Cortet B, et al. La vitamine D chez l'adulte : recommandations du GRIO. Presse Med 2011 ; 40 673-682.

2- Bischoff-Ferrari H, Willett W, Orav E et al. A pooled analysis of vitamin D dose requirements for fracture prevention. N Engl J Med 2012; 367: 40-49.

3- Bischoff-Ferrari H, Dawson-Hughes B, Staehelin HB et al. Fall prevention with supplemental and active forms of vitamin D: a meta-analysis of randomised controlled trials. BMJ 2009; 339: b3692

4- Carmel A, Shieh A, Bang H, Blockman R. The 25(OH)D level to maintain a favourable bisphosphonate response is $>33 \mathrm{ng} / \mathrm{mL}$. Osteoporos Int 2012; 23: 2479-2487.

5-Souberbielle JC, Body JJ, Lappe JM, et al. Vitamin D and musculoskeletal health, cardiovascular disease, autoimmunity and cancer: recommendations for clinical practice. Autoimmunity Reviews 2010; 9: 709-715.

6- Larsen T, Mose F, Bech J et al. Effect of cholecalciferol supplementation during winter months in patients with hypertension : a randomized placebo-controlled trial. Am J Hypertension 2012;

7-Mason C, Xiao L, Imayama I et al. Vitamin D3 supplementation during weight loss: a double-blind randomized controlled trial. Am J Clin Nutr 2014; 99: 1015-1025. 8-Holick M, Binkley N, Bischoff-Ferrari H et al. Evaluation, treatment and prevention of vitamin D deficiency: an Endocrine Society clinical practice guideline. J Clin Endocrinol Metab 2011; 96: 1911-1930.

9-Adams J, Hewison M. Update in vitamin D. J Clin Endocrinol Metab 2010; 95 : 471-478 10- Dawson-Hughes B, Mithal A, Bonjour JP et al. IOF position statements: vitamin D recommendations for older adults. Osteoporos Int 2010; 21: 1151-1154. 
11-Hanley D, Cranney A, Jones G, et al. Vitamin D in adult health and disease: a review and guideline statement from Osteoporosis Canada. CMAJ 2010 ; 182 : E610-E618.

12-Ross C, Manson JE, Abrams S et al. The 2011 report on dietary reference intakes for calcium and vitamin D from the Institute of Medicine : what clinicians need to know. J Clin Endocrinol Metab 2011; 96: 53-58.

13-Luxwolda M, Kuiperst R, Kema I, et al. Traditionnally living populations in East Africa have a mean serum 25-hydroxyvitamin D concentration of $115 \mathrm{nmol} / \mathrm{L}$. British Journal of Nutrition $2012 ; 108: 1557-1561$.

14-Hathcock J, Shao A, Vieth R, et al. Risk assessment for vitamin D. Am J Clin Nutr 2007; 85: $6-18$

15-Eisman J. When is a U-curve actually a J-curve? Is it really too much of a good thing? J Clin Endocrinol Metab 2013; 98: 1863-1864.

16-Souberbielle JC, Massart C, Brailly-Tabard S et al. Prevalence and determinants of vitamin D deficiency in healthy French adults: the VARIETE study. Endocrine. 2016;53: 54350.

17-Vernay M, Sponga M, Salanave B, et al. Statut en vitamine D de la population adulte en France : l'étude nationale nutrition santé (ENNS, 2006-2007). BEH 24 avril 2012 : 189-194. 18-Touvier M, Deschasaux M, Montourcy M et al. Interpretation of plasma PTH concentrations according to 25OHD status, gender, age, weight status, and calcium intake: importance of the reference values. J Clin Endocrinol Metab 2014; 99: 1196-1203.

19- Souberbielle JC, Benhamou CL, Cortet B, et al. Ostéopathies fragilisantes, maladie rénale chronique, malabsorptions, anomalies biologiques du métabolisme phospho-calcique : les bonnes indications pour un remboursement raisonné du dosage de vitamine D. Ann Biol Clin (Paris) $2015 ; 72:$ 385-389. 
20- Tafaro L, Nati G, Leoni E, et al. Adherence to anti-osteoporotic therapies: role and determinants of "spot therapy". Osteoporos Int 2013; 24: 2319-2323.

21-Armas LAG, Hollis BW, Heaney RP. Vitamin D2 is much less effective than vitamin D3 in humans. J Clin Endocrinol Metab 2004; 89: 5387-5391.

22- Sanders KM, Stuart AL, Williamson EJ, et al. Annual high-dose oral vitamin D and falls and fractures in older women: a randomized controlled trial. JAMA. 2010;303: 1815-1822. 23-Smith H, Anderson F, Raphael P, Maslin P, Crozier S, Cooper C. Effect of annual intramuscular vitamin D on fracture risk in elderly men and women - A population-based, randomized, double-blind, placebo-controlled trial. Rheumatology 2007; 46: 1852-1857. 24- Välimäki VV, Löyttyniemi E, Pekkarinen T, et al. How well are the optimal serum 25OHD concentrations reached in high-dose intermittent vitamin D therapy? a placebocontrolled study on comparison between 100000 IU and 200000 IU of oral D3 every 3 months in elderly women. Clin Endocrinol (Oxf). 2016;84:837-844.

25- Darling AL, Hart KH, Gibbs MA, et al. Greater seasonal cycling of 25-hydroxyvitamin D is associated with increased parathyroid hormone and bone resorption. Osteoporos Int. 2014;25: 933-941.

26- Ish-Shalom S, Segal E, Salganik T et al. Comparison of daily, weekly, and monthly vitamin D3 in ethanol dosing protocols for two months in elderly hip fracture patients. J Clin Endocrinol Metab 2008; 93: 3430-3435.

27-Bischoff-Ferrari H, Dawson-Hughes B, Orav E, et al. Monthly high-dose vitamin D treatment for the prevention of functional decline: a randomized clinical trial. JAMA Int Med. Doi:10.1001/jamainternmed.2015.7148.

28-Bischoff-Ferrari H, Dawson-Hughes B, Platz A, et al. Effect of high-dosage cholecalciferol and extended physiotherapy on complications after hip fracture. Arch Int Med 2010; 170: 813-820. 
29-Cummings S, Kiel DP, Black DM. Vitamin D supplementation and increased risk of falling: a cautionary tale of vitamin D supplement retold. JAMA Intern Med 2016; 176:171172.

30-Choi HS, Min Y-K, Byun DW, et al. Korean Society for Bone and Mineral research task force report: perspectives on intermittent high-dose vitamin D supplementation. J Bone Metab 2017; 24: 141-145.

31-Hollis B, Wagner C. The role of the parent compound vitamin D with respect to metabolism and function: why clinical dose intervals can affect clinical outcomes. J Clin Endocrinol Metab 2013; 98: 4619-4628.

32-Vieth R. How to optimize vitamin D supplementation to prevent cancer, based on cellular adaptation and hydroxylase enzymology. Anticancer Res 2009; 29: 3675-3784.

33-Muir S, Montero-Odasso M. Effect of vitamin D supplementation on muscle strength, gait and balance in older adults: a systematic review and meta-analysis. J Am Geriatr Soc 2011; 59: 2291-2300.

34-Martineau A, Jolliffe D, Hooper R, et al. Vitamin D supplementation to prevent acute respiratory tract infections: systematic review and meta-analysis of individual participant data. BMJ 2017; i6583 doi: 10.1136/bmj.6583.

35-Autier P, Gandini S, Mullie P. A Systematic Review : Influence of Vitamin D Supplementation on Serum 25-Hydroxyvitamin D Concentration. J Clin Endocrinol Metab 2012; 97: 2606-2613. 


\section{In patients with or at risk for osteoporosis}

Until daily dosing becomes feasible, intermittent dosing should remain standard practice, with the lowest available dosages and shorter dosing intervals. This strategy probably improves adherence compared to daily dosing.

- Start with a loading phase

50000 IU of vitamin D3 per week for 8 weeks in patients whose 25OHD is $<20$ $\mathbf{n g} / \mathbf{m L}$

50000 IU of vitamin D3 per week for 4 weeks in patients whose 25OHD is between 20 and $30 \mathrm{ng} / \mathrm{mL}$

- After this loading phase, prescribe long-term supplementation:

50000 IU of vitamin D3 per month

- After 3-6 months of this long-term supplementation, repeat the 25OHD assay

If $\mathbf{2 5 O H D}$ is still $<\mathbf{3 0} \mathbf{n g} / \mathbf{m L}$

- either shorten the dosing interval (e.g., 50000 IU every 2 weeks)

- or increase the dosage (e.g., to 80000 or 100000 IU each month)

If $250 \mathrm{HD}$ is $>60 \mathbf{n g} / \mathbf{m L}$ (extremely rare)

- The only possibility contradicts the recommendations above:

- increase the dosing interval (e.g., 50000 UI every 2 months) until lower dosages become available

Figure 1: Modalities of vitamin D supplementation for patients with vitamin D deficiency or insufficiency 